\title{
Model construction for field operation machinery selection and configuration in wheat-maize double cropping system
}

\author{
Fu Zhang ${ }^{1,2,3^{*}}$, Tianhua Chen ${ }^{1}$, Shuai Teng ${ }^{1}$, Jiajia Wang ${ }^{1}$, Ruiliang Xu ${ }^{4}$, Zhijun Guo ${ }^{4}$ \\ (1. College of Agricultural Equipment Engineering, Henan University of Science and Technology, Luoyang 471003, Henan, China; \\ 2. Key Laboratory of Modern Agricultural Equipment and Technology, Jiangsu University, Ministry of Education, Zhenjiang 212013, \\ Jiangsu, China;
}

3. Collaborative Innovation Center of Machinery Equipment Advanced Manufacturing of Henan Province, Luoyang 471003, Henan, China; 4. College of Vehicle \&Transportation Engineering, Henan University of Science and Technology, Luoyang 471003, Henan, China)

\begin{abstract}
In order to scientifically and reasonably select the field operation machinery in the wheat-maize double cropping system, first, the selection evaluation index system was constructed through the existing national standards and industry standards. Then the selection evaluation model was established based on the improved fuzzy comprehensive evaluation method. And the method of subjective weight and objective weight was used to overcome the drawbacks of the previous single weighting method that could not take into account the subject and object information of each indicator, and the weight value of each index was obtained in the evaluation system. Finally, the tillage process was used as an example, the field experiment was carried out to obtain the evaluation index value, and the model of selection evaluation was verified. The selection results of moldboard plough and rotary cultivator were as follows: the order of the comprehensive evaluation results of the moldboard plough results was ranked from high to low as 1LFK-435 $\left(\mathrm{II}_{\mathrm{M}}\right), 1 \mathrm{LFK}-535\left(\mathrm{I}_{\mathrm{M}}\right), 1 \mathrm{LF}-342\left(\mathrm{III}_{\mathrm{M}}\right), 1 \mathrm{LFT}-445\left(\mathrm{IV}_{\mathrm{M}}\right), 1 \mathrm{LFT}-545$ $\left(\mathrm{V}_{\mathrm{M}}\right)$, and the best machine type of the moldboard plough was $\mathrm{II}_{\mathrm{M}}$; the order of the comprehensive evaluation results of the rotary cultivator was ranked from high to low as $1 \mathrm{GQKGN}-240\left(\mathrm{III}_{\mathrm{R}}\right), 1 \mathrm{GKNSM}-250\left(\mathrm{IV}_{\mathrm{R}}\right), 1 \mathrm{GKN}-230 \mathrm{~K}\left(\mathrm{I}_{\mathrm{R}}\right), 1 \mathrm{GKN}-250 \mathrm{~K}$ $\left(\mathrm{II}_{\mathrm{R}}\right), 1 \mathrm{GQKGN}-220\left(\mathrm{~V}_{\mathrm{R}}\right)$, and the optimal model of the rotary cultivator was $\mathrm{III}_{\mathrm{R}}$. The experimental results showed that the results obtained by the evaluation model were in agreement with the local actual situation. The evaluation model will provide a scientific method for the selection of wheat and maize double cropping field operation machinery.
\end{abstract}

Keywords: wheat-maize double cropping system, agricultural machinery, parts selection mode, evaluation system, fuzzy comprehensive evaluation method, combination weight

DOI: $10.25165 /$ j.ijabe.20211404.6383

Citation: Zhang F, Chen T H, Teng S, Wang J J, Xu R L, Guo Z J. Model construction for field operation machinery selection and configuration in wheat-maize double cropping system. Int J Agric \& Biol Eng, 2021; 14(4): 82-89.

\section{Introduction}

With the rapid development of agricultural machinery and the layout of agricultural modernization, agricultural machinery in recent years has a huge share, and the types of agricultural machinery on the market are complex and diverse ${ }^{[1-5]}$. In order to ensure the quality of agricultural machinery products, according to the relevant laws and regulations of China, agricultural machinery needs to be tested by relevant departments before listing. However, due to the lack of scientific and reasonable guidelines for the selection of agricultural machinery by users in the production area, there are common problems such as unreasonable selection, excess function, low utilization, high cost, waste of resources, $\operatorname{etc}^{[6-8]}$. Based on this, scholars have launched relevant research

Received date: 2020-12-29 Accepted date: 2021-05-06

Biographies: Tianhua Chen, Master candidate, research interest: intelligent agricultural equipment and technology, Email: 954594709@qq.com; Shuai Teng, Master candidate, research interest: intelligent agricultural equipment and technology, Email: 285149837@qq.com; Jiajia Wang, PhD, Lecturer, research interest: biomechanics and bionic, Email: johnnyjiajia@163.com; Ruiliang Xu, Associate Professor, research interest: modern mechanism design method and application, Email: lyxrl@163.com; Zhijun Guo, PhD, Professor, research interest: biomimetic technology for ground machinery, Email: gzhj1970@163.com.

*Corresponding author: Fu Zhang, PhD, Professor, Assistant Dean, research interest: biomimetic technology and the intelligent agricultural equipment. College of Equipment Agricultural Engineering, Henan University of Science and Technology, Luoyang 471003, Henan, China. Tel: +86-13592065683, Email: zhangfu30@126.com. and achieved fruitful results ${ }^{[9-16]}$. As an example, Yang et al. ${ }^{[17]}$ combined with the characteristics of agricultural requirements of self-propelled micro-rotary cultivator and constructed the self-propelled micro-rotary cultivator comprehensive evaluation model and, based on the fuzzy mathematics comprehensive evaluation theory, the collective experience judgment method was adopted, weights were assigned to various factors, and the selection and quality evaluation were completed. Gong et al. ${ }^{[18]}$ aimed at the comprehensive evaluation of the application of plant protection machinery, the plant protection machinery evaluation system was constructed. The applicability evaluation for plant protection machinery was completed, with the analytic hierarchy process in terms of technical indicators, economic indicators, and operating conditions. Zhang et al. ${ }^{[19]}$ developed a type of Tobacco planting machinery, they took the ridging link raising process as an example, adopted the analytic hierarchy process, and combined the expert scoring method and the empirical method to construct the judgment matrix of indicators based on adopting. The weight set and the final selection evaluation result of the ridge raising machinery were obtained. $\mathrm{Fu}$ et al. $^{[20]}$ studied the selection of rice combine harvesters and used projection pursuit and genetic algorithm combined modeling, which overcame the influence of human subjective factors in the selection of agricultural machinery. Based on the experts' personal experience, weighting evaluation indicators such as operating cost, harvest loss rate, breakage rate, and reliability. Kang et al. ${ }^{[21]}$ used the second-class indefinite comprehensive judgment for the rice harvester was selected and 
evaluated. When studying the selection and evaluation of traditional combine harvesters, Wang et al. ${ }^{[22]}$ introduced the gray correlation method and constructed a data column of the necessity and safety evaluation index of the standby model to obtain the gray correlation degree, and then determined that it is suitable for the best model in the region. In the process of selecting biogas engineering technologies in the Wuhan area, the weight assignment process of the fuzzy comprehensive evaluation method was improved by Xiang et al. ${ }^{[23]}$, and finally, the optimal sequencing of biogas engineering technologies in this area was obtained.

In the past, the single weighting method was used to assign weights to the evaluation indexes on the selection of agricultural machinery, but the combination of subjective and objective weighting methods was rarely mentioned. Therefore, in order to conduct more scientific, reasonable, and comprehensive research on the selection and evaluation of agricultural machinery, this study was based on the fuzzy comprehensive evaluation method to establish a selection evaluation model for the field preparation link of wheat and maize field operation machinery, and clarify the evaluation at all levels. The index factor overcame the disadvantages of the previous single weighting method that cannot simultaneously take into account the index weight to the subject and object information. The fuzzy comprehensive evaluation method not only made the evaluation object hierarchical, but also reflected the ambiguity and uncertainty of the evaluation standard. The combined weights were obtained by using the AHP method and the entropy weight method, and the model with the highest evaluation was obtained through the weighted comprehensive average algorithm. The AHP was used to solve complex multi-objective problems, it can complete qualitative and quantitative decision analysis. The entropy weight method can effectively reflect the information implicit in the data, and enhance the difference and discrimination of indicators. Finally, the farmland link was taken as an example, the evaluation model was verified through experiments, which can be used for the evaluation of agricultural machinery selection theoretical research provides new methods and new ideas.

\section{Construction of an evaluation system for field machinery}

The southern area of Huang-Huai-Hai, represented by Henan Province, is mainly made of wheat and maize double-cropping products. Field research was carried out on the large seed industry bases, national demonstration bases and agricultural machinery cooperatives, which are representative of the central, eastern, western and northern Henan Province and have large scale and complete equipment for field operation machinery. The planting period of winter wheat is generally in early October, while the planting period of summer maize is in late June. Combining the actual process index system and production operation links of the mechanized production of wheat and maize double-cropping products, it is concluded that the planting process of wheat and maize double-cropping products involves a total of 7 operations, which are respectively tillage and land preparation, wheat sowing, field management, and harvesting, maize planting, field management, and harvesting. The specific operation flow chart is shown in Figure 1.

3 Establishment of the model of field machinery selection evaluation

\subsection{Model of field machinery selection evaluation}

The selection of agricultural machinery has the characteristics of complexity, uncertainty, and randomness, it has a clear connotation but it has also fuzzy extension. It is difficult to describe the problem with an absolute precise mathematical model. Therefore, this study established the evaluation model of field operation machinery selection based on the fuzzy mathematics theory, the difficult problems were quantified according to the membership function theory, and the qualitative evaluation was transformed the quantitative evaluation. The model of field machinery selection and evaluation is shown in Figure 2.

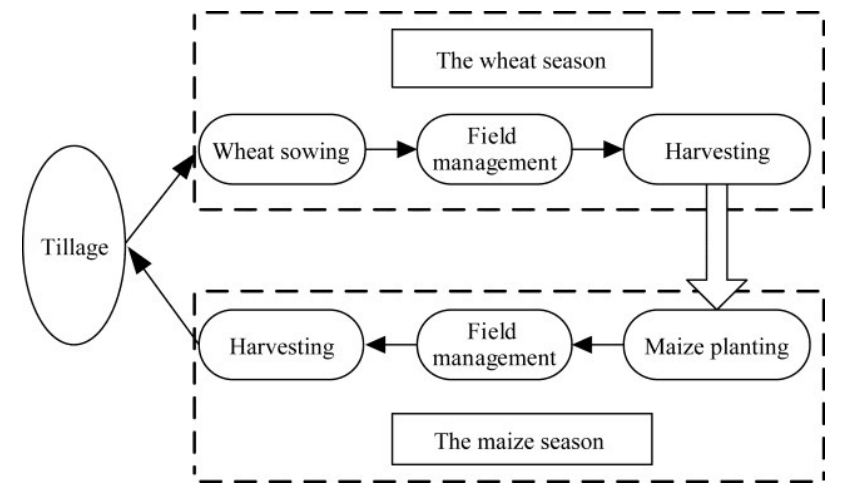

Figure 1 Flow chart of wheat and maize double cropping field operation

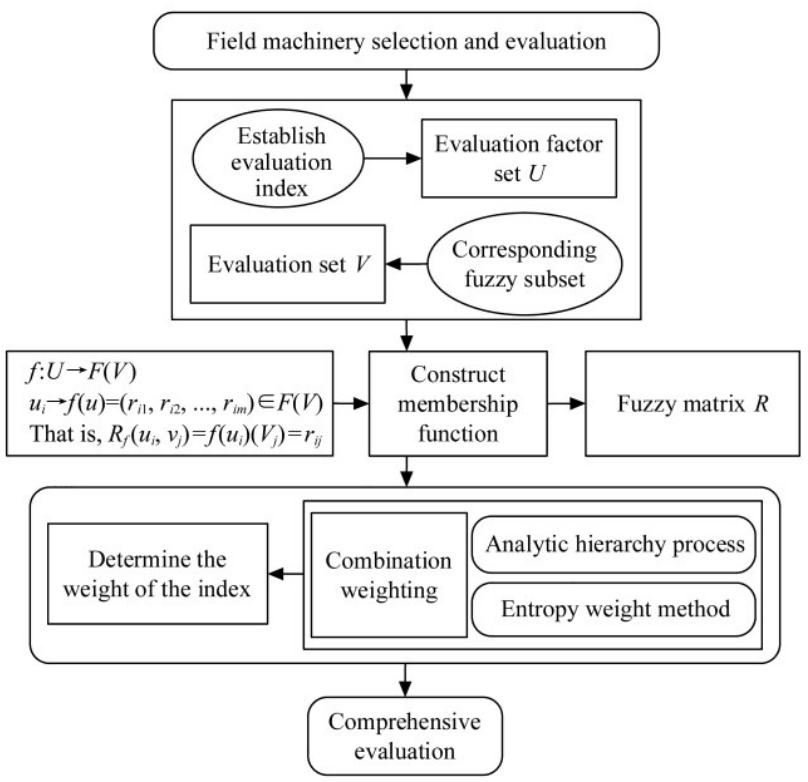

Figure 2 Model of field machinery selection evaluation

1) Setting of two finite fields

Based on the fuzzy mathematics theory and the actual situation, the study analyzed the influencing factors, the evaluation system of the agricultural machinery in the cultivated land link was established, and the factor set and the evaluation set were established.

$$
\begin{aligned}
& U=\left\{u_{1}, u_{2}, \ldots, u_{n}\right\} \quad(n=1,2,3, \ldots) \\
& V=\left\{v_{1}, v_{2}, \ldots, v_{m}\right\} \quad(m=1,2,3, \ldots)
\end{aligned}
$$

where, $U$ and $V$ are the factor set and evaluation set, respectively.

2) Establishment of membership function

The membership function $V=F(U)$ from $U$ to $V$ was established. Let the $i$-th factor in factor set $U$ be $u_{i}(i=1,2, \ldots, n)$, then $R_{i}=\left\{r_{i 1}\right.$, $\left.r_{i 2}, \ldots, r_{i m}\right\}(i=1,2,3, \ldots)$, it was the set of eigenvalues of the evaluation set, and then the fuzzy matrix $\boldsymbol{R}$ can be obtained.

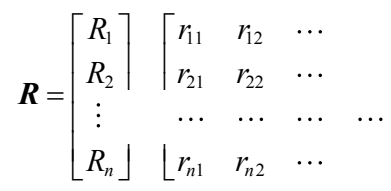


3) Determination of the membership matrix

Due to the different dimensions of each factor, the evaluation results in the membership matrix $\boldsymbol{R}$ should be normalized according to Equation (4).

$$
r_{i j}^{0}=\frac{r_{i j}}{\sum_{j}^{m}=1^{r_{i j}}}
$$

Thus, the normalized data $\boldsymbol{R}^{0}$ can be obtained,

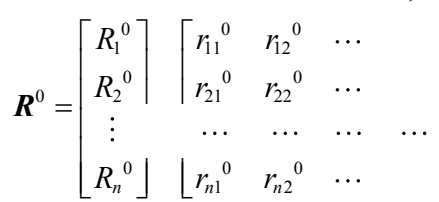

4) Comprehensive evaluation

The weighted average model was adopted to obtain the comprehensive evaluation index value. Supposing the weight of $U$ was $a_{i}(i=1, \ldots, n)$, then the weight vector of factor set was $\boldsymbol{A}=\left[a_{1}\right.$, $\left.a_{2}, \ldots, a_{n}\right]$.

The comprehensive evaluation matrix $\boldsymbol{B}$ of each index can be obtained by the following equation:

$$
\boldsymbol{B}=\boldsymbol{A} \cdot \boldsymbol{R}^{0}=\left[b_{1}, b_{2}, \ldots, b_{m}\right]
$$

where, $b_{i}(i=1,2, \ldots, m)$ represents the degree of membership of each evaluated model. According to the degree of membership of the model, the priority of machine selection can be determined by arranging in order.

\subsection{Principles of evaluation indicator setting}

Since there are many evaluation indicators involving evaluation objects, and they are used as an important basis for constructing membership functions in fuzzy comprehensive judgment and in the process of determining weights, the selection principle of evaluation indicators will affect the scientificity, rationality and accuracy of the comprehensive evaluation results which should follow the following principles ${ }^{[24,25]}$

1) The system principle. From the perspective of the system, the influence factors of each system are considered comprehensively for the evaluation object, so the selection evaluation system is reflected comprehensively and objectively.
2) Practical principles. The selected evaluation indexes can truly reflect the characteristics of the evaluation objects, and factors such as whether the index data of each operation link in the field can be easily obtained and whether the index quantization is operable.

3) Scientific principles. The evaluation object should be analyzed scientifically, and the evaluation indexes are constructed in combination with its main characteristics. The calculation methods and steps of each indicator must be evidence-based, scientific and reasonable.

4) The principle of regional adaptability. Since the agricultural planting patterns and planting agronomic standards are different in different regions, the evaluation indicators must have universal applicability and truly reflect the characteristics of the evaluation area.

5) Principle of combining quantitative and qualitative methods. In order to avoid the existence of indicators that are difficult to identify, the method of combining qualitative indicators obtained according to relevant evaluation criteria with quantitative indicators supported by objective data is selected.

\subsection{Classification of evaluation index}

In this study, the complex relationship of evaluation factors, as well as the availability of index data and the operability of the methods, were fully considered according to the unique attributes of each link operating machine. Referring to relevant research results, this study mainly selected three secondary indexes, namely economic cost, operation performance and use effect, which were closely related to the selection of agricultural machinery. On the basis of in-depth analysis of secondary indexes, the evaluation index system of twenty-seven tertiary indexes was constructed. The details are listed in Table 1. The operational performance indexes were mainly derived from the relevant national standards, industry standards and appraisal programs, which have been issued and implemented. The indexes of economic cost and use effect were mainly determined by literature review, field research and expert consultation.

Table 1 Cultivated land link machinery and tools evaluation indexes

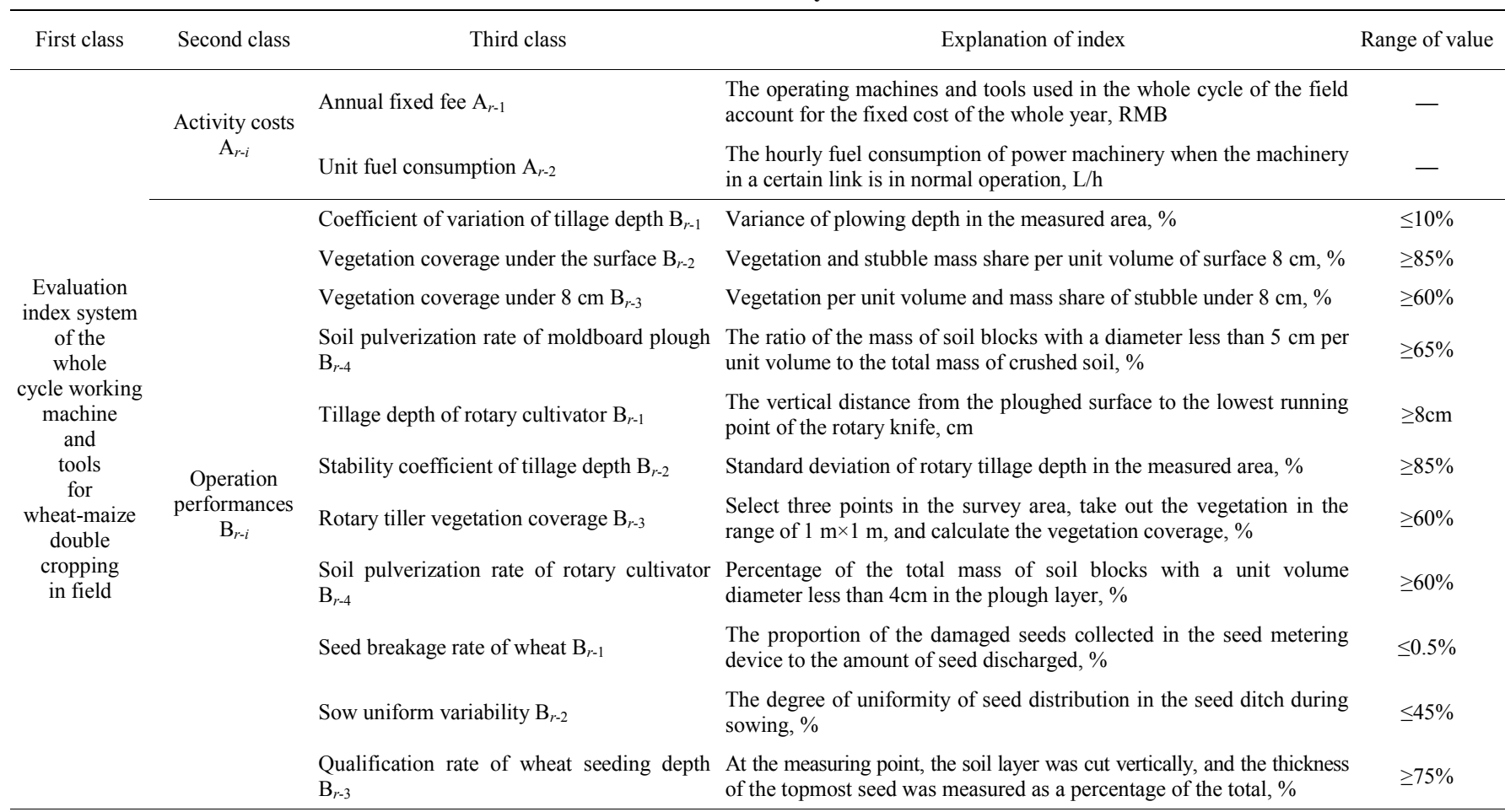




\begin{tabular}{|c|c|c|c|c|}
\hline First class & Second class & Third class & Explanation of index & Range of value \\
\hline \multirow{13}{*}{$\begin{array}{l}\text { Evaluation } \\
\text { index system } \\
\text { of the } \\
\text { whole } \\
\text { cycle working } \\
\text { machine } \\
\text { and } \\
\text { tools } \\
\text { for } \\
\text { wheat-maize } \\
\text { double } \\
\text { cropping } \\
\text { in field }\end{array}$} & \multirow{12}{*}{$\begin{array}{l}\text { Operation } \\
\text { performances } \\
\mathrm{B}_{r-i}\end{array}$} & $\begin{array}{l}\text { Coefficient of variation of stability of } \\
\text { fertilizer discharge } \mathrm{B}_{r-4}\end{array}$ & Standard deviation of fertilizer discharge under required conditions, \% & $\leq 7.8 \%$ \\
\hline & & Total wheat loss ratio $\mathrm{B}_{r-1}$ & Percentage of grain mass lost by harvester to total grain mass, $\%$ & $\leq 1.2 \%$ \\
\hline & & Wheat yield breakage rate $\mathrm{B}_{r-2}$ & $\begin{array}{l}\text { The percentage of the total grain mass of the grain harvested due to } \\
\text { mechanical damage caused by crack breakage, } \%\end{array}$ & $\leq 1.0 \%$ \\
\hline & & Wheat impurity rate $\mathrm{B}_{r-3}$ & $\begin{array}{l}\text { Grain combine harvester, the percentage of non-grain impurities } \\
\text { contained in the harvest to its total mass, } \%\end{array}$ & $\leq 2.0 \%$ \\
\hline & & Seed breakage rate of maize $\mathrm{B}_{r-1}$ & $\begin{array}{l}\text { The percentage of damaged seeds discharged by the seed metering } \\
\text { device to the number of seeds discharged, } \%\end{array}$ & $\leq 1.5 \%$ \\
\hline & & Maize sowing repetition rate $\mathrm{B}_{r-2}$ & $\begin{array}{l}\text { In-line precision sowing of single grain, the percentage of the number of } \\
\text { plants with seed spacing less than or equal to } 0.5 \text { times the theoretical } \\
\text { distance to the total number of measured plants, } \%\end{array}$ & $\leq 15 \%$ \\
\hline & & Missed rate of maize sowing $\mathrm{B}_{r-3}$ & $\begin{array}{l}\text { In-line precision sowing of single grain, the percentage of the number of } \\
\text { plants whose seed distance is more than } 1.5 \text { times the theoretical } \\
\text { distance to the total number of measured plants, } \%\end{array}$ & $\leq 8.0 \%$ \\
\hline & & $\begin{array}{l}\text { Coefficient of variation of stability of } \\
\text { fertilizer discharge } \mathrm{B}_{r-4}\end{array}$ & Standard deviation of fertilizer discharge under required conditions, $\%$ & $\leq 7.8 \%$ \\
\hline & & $\begin{array}{l}\text { Crushing rate of harvested maize kernels } \\
\mathrm{B}_{r-1}\end{array}$ & $\begin{array}{l}\text { The damaged grains were picked out from the outlet of the spike lifter } \\
\text { or the grain receiving outlet of not less than } 2 \mathrm{~kg} \text {, and the weight of } \\
\text { damaged grains and the percentage of the total weight of grains in the } \\
\text { sample were weighed respectively, } \%\end{array}$ & $\leq 1.0 \%$ \\
\hline & & $\begin{array}{l}\text { Impurity content in ear of harvested } \\
\text { maize } \mathrm{B}_{r-2}\end{array}$ & $\begin{array}{l}\text { In the measuring area, the total mass and the percentage of sundry mass } \\
\text { of the outlet of the receiving ear lifter were respectively weighed, } \%\end{array}$ & $\leq 1.5 \%$ \\
\hline & & $\begin{array}{l}\text { Bract stripping rate of harvested maize } \\
\mathrm{B}_{r-3}\end{array}$ & $\begin{array}{l}\text { In the measured area, the percentage of the total weight of the ear with } \\
\text { more than or equal to } 3 \text { bracts (more than } 2 / 3 \text { whole leaves) was picked } \\
\text { out from the ear elevator outlet, } \%\end{array}$ & $\geq 85 \%$ \\
\hline & & $\begin{array}{l}\text { Qualified rate of straw crushing length } \\
\mathrm{B}_{r-4}\end{array}$ & $\begin{array}{l}\text { The percentage of the quality of crushing length in the total mass of } \\
\text { straw returned to the field, \% }\end{array}$ & $\geq 85 \%$ \\
\hline & Use effects $\mathrm{C}_{r-i}$ & Machine reliability $\mathrm{C}_{r-1}$ & $\begin{array}{l}\text { The probability that the machine can work normally within the specified } \\
\text { service life and under predetermined environmental conditions, } \%\end{array}$ & -- \\
\hline
\end{tabular}

\section{Determination method of the weight of evaluation index}

In order to avoid the neglect of the indicator weights in the past and the single weighting method that cannot take into account each disadvantage of indicator host and guest information, the method of combining subjective and objective to obtain the optimal combination weight to determine the weight of each index in the evaluation system is adopted in this study.

\subsection{Determination method of subjective weight}

The subjective weight adopted the analytic hierarchy process (AHP) to confirm the weight of the evaluation index. The evaluation index was divided into three levels, then, the comparative judgment matrix of two indicators was constructed according to the 1-9 scale method and scored by experts. After determining the relative importance of the indicators, the weight vector was calculated for the consistency test, and the weights of all levels of technical indicators in the wheat and maize double cropping field operating machinery index system were obtained. The weight determination process is shown in Figure 3.

1) Construction of judgment matrix

Let $\boldsymbol{A}$ represent the goal, $u_{i}, u_{j}(i, j=1,2, \ldots, n)$ represent the factors. $u_{i j}$ represents the relative importance of $u_{i}$ to $u_{j}$, and the judgment matrix $\boldsymbol{P}$ is obtained.

$$
\boldsymbol{P}=\left[\begin{array}{cccc}
u_{11} & u_{12} & \cdots & \\
u_{21} & u_{22} & \cdots & \\
\vdots & \vdots & \vdots \\
u_{n 1} & u_{n 2} & \cdots & \vdots
\end{array}\right.
$$

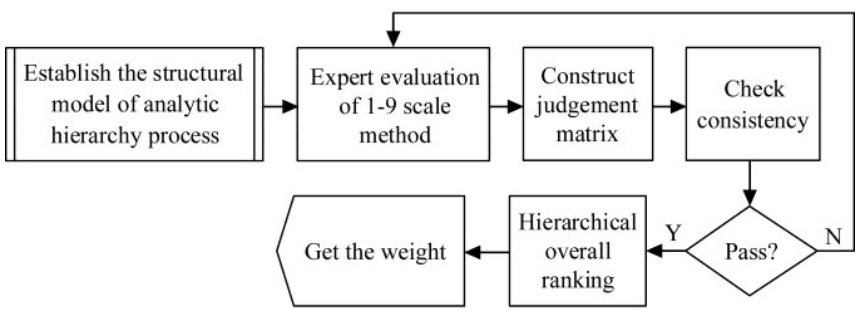

Figure 3 Flow chart of weight determination of analytic hierarchy process

2) Determination of relative importance of indicators

According to the following equation of the judgment matrix, the eigenvector $w$ corresponding to the largest eigenvalue $\lambda_{\max }$ can be calculated. Finally, after normalization treatment, the order of importance of each evaluation factor can be obtained, namely weight allocation.

3) Consistency check

$$
\boldsymbol{P}_{w}=\lambda_{\max } \cdot w
$$

The consistency of the obtained weight distribution was checked, it was given by Equation (9).

$$
C_{R}=\frac{C_{I}}{R_{I}}
$$

where, $C_{R}$ is the random consistency ratio; $C_{I}$ is the general consistency index. It was given by the following equation:

$$
C_{I}=\frac{\lambda_{\max }-n}{n-1}
$$

$R_{I}$ is a random consistency index. In general, when $C_{R}<0.1$ or $\lambda_{\max }=n$ and $C_{I}=0$ of the judgment matrix $\boldsymbol{P}, \boldsymbol{P}$ was considered to have satisfactory consistency; otherwise, elements in $\boldsymbol{P}$ need to be 
adjusted. $\quad R_{I}$ values of the judgment matrix of order 1-9 are listed in Table 2 below.

Table 2 Consistency index RI in mothed of AHP

\begin{tabular}{cc}
\hline Order-number $n$ & RI \\
\hline 1 & 0 \\
2 & 0 \\
4 & 0.58 \\
5 & 0.90 \\
6 & 1.12 \\
7 & 1.24 \\
8 & 1.32 \\
9 & 1.41 \\
\hline
\end{tabular}

\subsection{Determination method of objective weight}

Entropy is a measure of the uncertainty of a random variable, and as a function to describe the state of a material system, the greater the entropy is, the smaller the degree of variation of a certain attribute of the system, and the smaller the information contained. Conversely, the greater the degree of variation is, the smaller the entropy, and the larger the information. The calculation steps are as follows:

1) Construction of the original matrix of evaluation target indicators

Assuming that there are $n$ evaluation indexes and $m$ evaluation objects in the evaluation index system, and denoting them as $\boldsymbol{C}=\left\{C_{1}, C_{2}, C_{3}, \ldots, C_{n}\right\}, \boldsymbol{S}=\left\{S_{1}, S_{2}, S_{3}, \ldots, S_{m}\right\}$, the index matrix of the original evaluation object is expressed as follows:

$$
\boldsymbol{B}=\left(\begin{array}{ccc}
b_{11} & \cdots & \\
\vdots & \ddots & \vdots \\
b_{m 1} & \cdots &
\end{array}\right.
$$

2) Calculation of specific gravity $P_{i j}$

$$
P_{i j}=\frac{r_{i j}}{\sum_{i=1}^{m} r_{i j}}
$$

3) Determination of the entropy

$$
h_{j}=-(\ln n)^{-1} \sum_{i=1}^{m} P_{i j} \ln P_{i j}, 0 \leq h_{j} \leq 1
$$

4) Determination of the degree of variation coefficient

$$
a_{j}=1-h_{j}, j=1,2, \ldots, n
$$

5) Calculation of the objective weight

$$
W_{k j}=\frac{a_{j}}{\sum_{j=1}^{n} a_{j}}, j=1,2, \cdots
$$

\subsection{Optimal weighting combination}

After obtaining the subjective weight vector $\boldsymbol{W}_{c i}=\left(W_{c 1}, W_{c 2}, \ldots\right.$, $\left.W_{c i}\right)(c=1,2,3, \ldots)$ determined by the analytic hierarchy process, and the objective weight vector $\boldsymbol{W}_{k i}=\left(W_{k 1}, W_{k 2}, \ldots, W_{k i}\right)(k=1,2$, $3, \ldots$ ) were determined by the entropy weight method, the weight of the evaluation index was determined by the following equation:

$$
W_{i}=\frac{W_{c i} W_{k i}}{\sum W_{c i} W_{k i}}, i=1,2, \cdots
$$

The weight vector is $\boldsymbol{W}_{i}=\left(W_{1}, W_{2}, \ldots, W_{m}\right)$.

\section{Construction of membership function}

\subsection{Membership function of moldboard plough}

1) Annual fixed fee

Since the market price of machines and tools was completely operated in accordance with the market behavior, the price is not capped in this study, but the cost was more than 0 million, therefore, the membership function of the annual fixed fee can be expressed by the following equation:

$$
f(x)=\left\{\begin{array}{cc}
1, & x \leq 0 \\
e^{-x}, & x>0
\end{array}\right.
$$

2) Unit fuel consumption

Since the diesel engine has a diesel density of $0.83-0.85 \mathrm{~kg} / \mathrm{L}$ and a calorific value of $33000000 \mathrm{~J} / \mathrm{kg}$, according to the energy utilization rate of $25 \%-35 \%$, the fuel consumption of the tractor at full load can be calculated as 5-58 L. Therefore, the fuel consumption membership function can be expressed as follows:

$$
f(x)=\left\{\begin{array}{cc}
1, & x \leq 5 \\
\frac{58-x}{53}, & 5<x \leq 58 \\
0, & x>58
\end{array}\right.
$$

3) Depth stability

The national standard (GB/T14225-2008) $)^{[26]}$ stipulates that the coefficient of variation of stability of the plowshare depth should not be more than $10 \%$. Therefore, the subordinate function of the coefficient of variation of stability of the plowshare depth can be expressed as follows:

$$
f(x)=\left\{\begin{array}{cc}
1, & x \leq 0 \\
\frac{0.1-x}{0.1}, & 0<x \leq 0.1 \\
0, & x>0.1
\end{array}\right.
$$

4) Vegetation coverage rate of $8 \mathrm{~cm}$ below the surface

According to Reference [26], the subsurface vegetation coverage rate is greater than or equal to $85 \%$. Therefore, the subsurface vegetation coverage rate of $8 \mathrm{~cm}$ can be expressed as follows:

$$
f(x)=\left\{\begin{array}{cc}
0, & x \leq 0.85 \\
\frac{x-0.85}{0.15}, & 0.85<x \leq 1 \\
1, & x>1
\end{array}\right.
$$

5) Coverage rate of vegetation below $8 \mathrm{~cm}$ depth

According to the national standard of share plough $(\mathrm{GB} / \mathrm{T} 14225-2008)^{[26]}$, the vegetation coverage under a depth of 8 $\mathrm{cm}$ is greater than or equal to $60 \%$. Therefore, the vegetation coverage rate under a depth of $8 \mathrm{~cm}$ could be represented by the following equation:

$$
f(x)=\left\{\begin{array}{cc}
0, & x \leq 0.6 \\
\frac{x-0.6}{0.4}, & 0.6<x \leq 1 \\
1, & x>1
\end{array}\right.
$$

6) Broken soil rate

According to the industry standard of operating quality of share plough (NY/T742-2003) $)^{[27]}$, it is greater than or equal to $65 \%$. Therefore, the membership function of soil fragmentation rate can be expressed as follows:

$$
f(x)=\left\{\begin{array}{cc}
0, & x \leq 0.65 \\
\frac{x-0.65}{0.4}, & 0.65<x \leq 1 \\
1, & x>1
\end{array}\right.
$$

7) Validity

According to the promotion and appraisal outline of moldboard agricultural Machinery (DG/T087-2019) ${ }^{[28]}$, the validity is greater than or equal to $98 \%$, so the validity membership function can be expressed by the following equation: 


$$
f(x)=\left\{\begin{array}{cc}
0, & x \leq 0.98 \\
\frac{x-0.98}{0.02}, & 0.98<x \leq 1 \\
1, & x>1
\end{array}\right.
$$

8) Product satisfaction

According to the promotion and appraisal outline of plow agricultural machinery (DG/T087-2019), the product satisfaction is greater than or equal to $80 \%$, so the product satisfaction membership function can be expressed by the following equation:

$$
f(x)=\left\{\begin{array}{cc}
0, & x \leq 0.8 \\
\frac{x-0.8}{0.2}, & 0.8<x \leq 1 \\
1, & x>1
\end{array}\right.
$$

\subsection{Rotary cultivator membership function}

1) Annual fixed fee

The membership function of the annual fixed fee of the rotary cultivator can also be expressed by Equation (17).

2) Unit fuel consumption

The membership function of unit fuel consumption of rotary cultivator can also be expressed in Equation (18).

3) Tillage depth of rotary cultivator

According to the national standard of rotary cultivator $(\mathrm{GB} / \mathrm{T} 5668-2017)^{[29]}$, the tillage depth of the rotary cultivator should not be less than $8 \mathrm{~cm}$, and the maximum is not more than $30 \mathrm{~cm}$. Therefore, the membership function of the tillage depth can be expressed as follows:

$$
f(x)=\left\{\begin{array}{cc}
0, & x \leq 8 \\
\frac{x-8}{22}, & 8<x \leq 30 \\
1, & x \geq 30
\end{array}\right.
$$

4) Rotary cultivator depth stability

According to the national standard of rotary cultivator $(\mathrm{GB} / \mathrm{T} 5668-2017)^{[29]}$, the qualified rate of rotary cultivator's tillage depth should not be less than $85 \%$. Therefore, the membership function of the rotary cultivator's tillage stability can be expressed as follows:

$$
f(x)=\left\{\begin{array}{cc}
0, & x \leq 0.85 \\
\frac{x-0.85}{0.15}, & 0.85<x \leq 1 \\
1, & x \geq 1
\end{array}\right.
$$

5) Broken soil rate of rotary cultivator

According to the national standard of rotary cultivator $(\mathrm{GB} / \mathrm{T} 5668-2017)^{[29]}$, the soil crushing rate of rotary cultivator after the operation cannot be less than $60 \%$. Therefore, the subjection function of soil crushing rate of rotary cultivator can be expressed as follows:

$$
f(x)=\left\{\begin{array}{cc}
0, & x \leq 0.6 \\
\frac{x-0.6}{0.4}, & 0.6<x \leq 1 \\
1, & x>1
\end{array}\right.
$$

6) Rotary cultivator vegetation coverage

According to the national standard of rotary cultivators $(\mathrm{GB} / \mathrm{T} 5668-2017)^{[29]}$, the vegetation coverage of rotary cultivators is greater than or equal to $60 \%$. Therefore, the vegetation coverage membership function can be expressed as follows:

$$
f(x)=\left\{\begin{array}{cc}
0, & x \leq 0.6 \\
\frac{x-0.6}{0.4}, & 0.6<x \leq 1 \\
1, & x>1
\end{array}\right.
$$

7) Validity

The membership function of the effectiveness of the rotary cultivator can also be expressed by Equation (23).

8) Product satisfaction

The membership function of product satisfaction of the rotary cultivator can also be expressed by Equation (24).

\section{Verification of the selection and evaluation model}

\subsection{Test conditions}

The experiment was carried out in 2017-2018 at Pingan Seed Industry Base in Jiaozuo City, Henan Province, China $\left(112^{\circ} 51^{\prime} 39^{\prime \prime} \mathrm{E}-113^{\circ} 13^{\prime} 20^{\prime \prime} \mathrm{E}, 34^{\circ} 52^{\prime} 00^{\prime \prime} \mathrm{N}-35^{\circ} 2^{\prime} 48^{\prime \prime} \mathrm{N}\right)$. The region has a warm temperate continental monsoon climate, with an average annual temperature of $14.3^{\circ} \mathrm{C}$, annual precipitation of $552.4 \mathrm{~mm}$, and a frost-free period of $219 \mathrm{~d}$, the soil type is loam. Generally, in the process of plowing and soil preparation, in order to ensure the quality of sowing soil and prevent large soil blocks from appearing after plowing operations, continuous plowing operations and rotation operations were often used. Generally, in the link of plowing and soil preparation, in order to ensure the quality of sowing soil and prevent larger soil blocks after plowing operations, continuous plowing operations and rotation operations were often used, and five moldboard ploughs 1LFK-535 $\left(\mathrm{I}_{\mathrm{M}}\right)$, 1LFK-435 (II $\left.\mathrm{I}_{\mathrm{M}}\right), 1 \mathrm{LF}-342\left(\mathrm{III}_{\mathrm{M}}\right), 1 \mathrm{LFT}-445\left(\mathrm{IV}_{\mathrm{M}}\right), 1 \mathrm{LFT}-545\left(\mathrm{~V}_{\mathrm{M}}\right)$ and five rotary cultivators $1 \mathrm{GKN}-230 \mathrm{~K}\left(\mathrm{I}_{\mathrm{R}}\right), 1 \mathrm{GKN}-250 \mathrm{~K}\left(\mathrm{II}_{\mathrm{R}}\right)$, 1GQKGN-240 (III $), 1 \mathrm{GKNSM-250}\left(\mathrm{IV}_{\mathrm{R}}\right), 1 \mathrm{GQKGN}-220\left(\mathrm{~V}_{\mathrm{R}}\right)$ were used for the experiment, respectively. The parameters and basics of the test machines are listed in Table 3. The testing process of field operation machinery was as follows. Firstly, the parameters such as annual fixed cost, number of operators and cost of operating units were collected, and the unit fuel consumption and effective operating time were recorded during operation. Secondly, during the test, the candidate models were numbered I-V, and the soil physical information of the test plot was collected. Moldboard plough test environment is that of previous crop maize, vegetation density of $374 \mathrm{~g} / \mathrm{m}^{2}$, soil of loam, water content of $13.1 \%$, firmness of $793 \mathrm{kPa}$. Rotary cultivator test environment, the soil type was loam, the water content was $15.4 \%$, the firmness was $463 \mathrm{kPa}$, the vegetation coverage before cultivated land was $146 \mathrm{~g} / \mathrm{m}^{2}$, and the test data of land preparation link are listed in Table 4.

\subsection{Evaluation results and analysis}

According to the established evaluation model, the individual indexes and weights of the alternative models of moldboard plough and rotary cultivator in Table 5 were normalized, and finally, the weighted comprehensive average algorithm was adopted. Finally, the index data and its corresponding combined weight value were multiplied by Equation (6), the comprehensive evaluation result of the moldboard plow and rotary cultivator were obtained, moldboard plow and rotary cultivator were used in the field link of wheat and maize double crop production. The evaluation results are shown in Figure 4.

From the point of comprehensive evaluation results, moldboard plough machine I-V comprehensive evaluation indexes were $0.1572,0.1609,0.1449,0.1257$ and 0.1026 . The comprehensive evaluation results of the share plough machine and tools were ranked from high to low as $\mathrm{II}_{\mathrm{M}}, \mathrm{I}_{\mathrm{M}}, \mathrm{III}_{\mathrm{M}}, \mathrm{IV}_{\mathrm{M}}, \mathrm{V}_{\mathrm{M}}$, and the optimal type of moldboard plough was $\mathrm{II}_{\mathrm{M}}$; Rotary cultivator machines $I_{R}-V_{R}$ comprehensive evaluation indexes were 0.1489 , $0.1473,0.1564,0.1543$ and 0.0159 . The comprehensive evaluation results of rotary tiller were ranked from high to low as $I I I_{R}, I V_{R}, I_{R}, I I_{R}, V_{R}$, the optimal type of rotary tiller was $\mathrm{III}_{R}$. 
Table 3 Basic parameters and information of ridging machine

\begin{tabular}{|c|c|c|c|c|c|}
\hline Tool name & No. & Machine model & Power/kw & Width/cm & Velocity $/ \mathrm{km} \cdot \mathrm{h}^{-1}$ \\
\hline \multirow{5}{*}{$\begin{array}{l}\text { Moldboard } \\
\text { plough }\end{array}$} & $\mathrm{I}_{\mathrm{M}}$ & 1LFK-535 & $73.5-120.0$ & 350 & 5.30 \\
\hline & $\mathrm{II}_{\mathrm{M}}$ & 1LFK-435 & $66.2-120.0$ & 350 & 5.40 \\
\hline & $\mathrm{III}_{\mathrm{M}}$ & $1 \mathrm{LF}-342$ & $99.2-120.0$ & 420 & 5.50 \\
\hline & $\mathrm{IV}_{\mathrm{M}}$ & 1LFT-445 & $110.5-120.0$ & 450 & 5.30 \\
\hline & $\mathrm{V}_{\mathrm{M}}$ & 1LFT-545 & $110.5-120.0$ & 450 & 5.20 \\
\hline \multirow{5}{*}{$\begin{array}{l}\text { Rotary } \\
\text { cultivator }\end{array}$} & $\mathrm{I}_{\mathrm{R}}$ & $1 \mathrm{GKN}-230 \mathrm{~K}$ & $66.2-120.0$ & 231 & 3.00 \\
\hline & $\mathrm{II}_{\mathrm{R}}$ & $1 \mathrm{GKN}-250 \mathrm{~K}$ & $73.5-120.0$ & 249 & 3.40 \\
\hline & $\mathrm{III}_{\mathrm{R}}$ & $1 \mathrm{GQKGN}-240$ & $95.5-120.0$ & 250 & 3.10 \\
\hline & $I V_{R}$ & 1GKNSM-250 & $110.3-120.0$ & 245 & 2.70 \\
\hline & $\mathrm{V}_{\mathrm{R}}$ & $1 \mathrm{GQKGN}-220$ & $73.5-120.0$ & 230 & 3.00 \\
\hline
\end{tabular}

Table 4 Experiment data of soil preparation part

\begin{tabular}{cccccccccc}
\hline Tool name & \multicolumn{10}{c}{ Test data } \\
\hline & No. & $\mathrm{A}_{1-1}$ & $\mathrm{~A}_{1-2}$ & $\mathrm{~B}_{1-1}$ & $\mathrm{~B}_{1-2}$ & $\mathrm{~B}_{1-3}$ & $\mathrm{~B}_{1-4}$ & $\mathrm{C}_{1-1}$ & $\mathrm{C}_{1-2}$ \\
& $\mathrm{I}_{\mathrm{M}}$ & 3093.75 & 21.68 & 2.6 & 87.9 & 63.7 & 69.2 & 100 & 100 \\
$\begin{array}{c}\text { Moldboard } \\
\text { plough }\end{array}$ & $\mathrm{II}_{\mathrm{M}}$ & 2025.00 & 20.06 & 2.8 & 87.0 & 63.7 & 70.5 & 100 & 100 \\
& $\mathrm{III}_{\mathrm{M}}$ & 2700.00 & 30.26 & 3.9 & 88.5 & 62.1 & 72.7 & 100 & 100 \\
& $\mathrm{IV}_{\mathrm{M}}$ & 2250.00 & 39.67 & 4.0 & 88.8 & 66.5 & 70.6 & 100 & 100 \\
& $\mathrm{~V}_{\mathrm{M}}$ & 2925.00 & 45.15 & 3.8 & 88.9 & 68.5 & 70.4 & 100 & 100 \\
\hline \multirow{4}{*}{$\begin{array}{c}\text { Rotary } \\
\text { cultivator }\end{array}$} & $\mathrm{No.}$ & $\mathrm{A}_{2-1}$ & $\mathrm{~A}_{2-2}$ & $\mathrm{~B}_{2-1}$ & $\mathrm{~B}_{2-2}$ & $\mathrm{~B}_{2-3}$ & $\mathrm{~B}_{2-4}$ & $\mathrm{C}_{2-1}$ & $\mathrm{C}_{2-2}$ \\
& $\mathrm{I}_{\mathrm{R}}$ & 956.25 & 20.12 & 15.1 & 96.4 & 81.6 & 90.4 & 100 & 100 \\
& $\mathrm{III}_{\mathrm{R}}$ & 1125.00 & 27.70 & 15.6 & 95.2 & 76.2 & 85.6 & 100 & 100 \\
& $\mathrm{IV}_{\mathrm{R}}$ & 900.00 & 33.75 & 13.7 & 92.8 & 86.6 & 89.8 & 100 & 100 \\
& $\mathrm{~V}_{\mathrm{R}}$ & 675.00 & 22.56 & 15.3 & 95.8 & 76.2 & 87.1 & 100 & 100
\end{tabular}

Note: Moldboard plough, $A_{1-1}$ is the annual fixed fee; $A_{1-2}$ is the unit oil consumption; $B_{1-1}$ is the coefficient of variation of tillage depth; $B_{1-2}$ is the $8 \mathrm{~cm}$ vegetation coverage under the surface; $\mathrm{B}_{1-3}$ is the vegetation coverage under 8 $\mathrm{cm}$; $\mathrm{B}_{1-4}$ is the rate of soil pulverization; $\mathrm{C}_{1-1}$ is the machine reliability; $\mathrm{C}_{1-2}$ is the operation safety. Rotary cultivator, $A_{2-1}$ is the annual fixed fee; $A_{2-2}$ is the unit oil consumption; $\mathrm{B}_{2-1}$ is the tilling depth; $\mathrm{B}_{2-2}$ is the stability coefficient of tillage depth; $B_{2-3}$ is the vegetation coverage; $B_{2-4}$ is the rate of soil pulverization; $C_{2-1}$ is the machine reliability; $\mathrm{C}_{2-2}$ the is operation safety, the same as below.

Table 5 Normalization and weighted results of index data

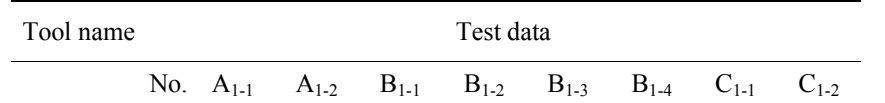

$\begin{array}{lllllllll}\mathrm{I}_{\mathrm{M}} & 0.1612 & 0.1493 & 0.1625 & 0.0417 & 0.0198 & 0.0264 & 0.2196 & 0.2196\end{array}$

$\begin{array}{lllllllll}\mathrm{II}_{\mathrm{M}} & 0.1765 & 0.1535 & 0.1556 & 0.0281 & 0.0195 & 0.0346 & 0.2161 & 0.2161\end{array}$

$\begin{array}{lllllllll}\mathrm{III}_{\mathrm{M}} & 0.1750 & 0.1123 & 0.1398 & 0.0527 & 0.2292 & 0.0504 & 0.2292 & 0.2292\end{array}$

$\begin{array}{lllllllll}\text { Moldboard } \mathrm{IV}_{\mathrm{M}} & 0.1832 & 0.0941 & 0.1377 & 0.0528 & 0.0367 & 0.0367 & 0.2294 & 0.2294\end{array}$

$\begin{array}{llllllllll}\mathrm{V}_{\mathrm{M}} & 0.1766 & 0.0568 & 0.1467 & 0.0615 & 0.0497 & 0.0355 & 0.2366 & 0.2366\end{array}$

$\begin{array}{llllllllll}\mathrm{Q}_{\mathrm{h} 1} & 0.0184 & 0.1658 & 0.0087 & 0.0053 & 0.0029 & 0.0317 & 0.6712 & 0.0959\end{array}$

$\begin{array}{lllllllll}\mathrm{Q}_{\mathrm{h} 2} & 0.4335 & 0.3671 & 0.0167 & 0.0275 & 0.1164 & 0.0206 & 0.0028 & 0.0154\end{array}$

$\begin{array}{llllllllll}\mathrm{Q}_{\mathrm{h} 3} & 0.0861 & 0.6569 & 0.0157 & 0.0157 & 0.0364 & 0.0704 & 0.0202 & 0.0159\end{array}$

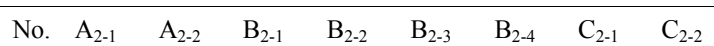

$\begin{array}{lllllllll}\mathrm{I}_{\mathrm{R}} & 0.1541 & 0.1204 & 0.0373 & 0.1288 & 0.0915 & 0.1288 & 0.1695 & 0.1695\end{array}$

$\begin{array}{lllllllll}\mathrm{II}_{\mathrm{R}} & 0.1535 & 0.1106 & 0.0407 & 0.1089 & 0.1223 & 0.1290 & 0.1676 & 0.1676\end{array}$

$\begin{array}{llllllllll}\mathrm{III}_{\mathrm{R}} & 0.1669 & 0.0859 & 0.0523 & 0.1270 & 0.0747 & 0.1195 & 0.1868 & 0.1868\end{array}$

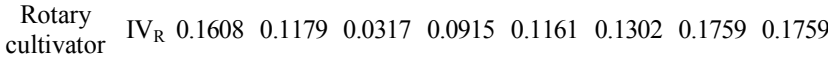

$\begin{array}{lllllllll}\mathrm{V}_{\mathrm{R}} & 0.1680 & 0.1024 & 0.0467 & 0.1294 & 0.0719 & 0.1222 & 0.1797 & 0.1797\end{array}$

$\begin{array}{lllllllll}\mathrm{Q}_{\mathrm{x} 1} & 0.6257 & 0.0894 & 0.0889 & 0.1049 & 0.0174 & 0.0175 & 0.0505 & 0.0560\end{array}$

$\begin{array}{lllllllll}\mathrm{Q}_{\mathrm{x} 2} & 0.4742 & 0.4214 & 0.0446 & 0.0126 & 0.0224 & 0.0030 & 0.0042 & 0.0175\end{array}$

$\begin{array}{lllllllll}\mathrm{Q}_{\mathrm{x} 3} & 0.8693 & 0.1103 & 0.0116 & 0.0039 & 0.0011 & 0.0001 & 0.0006 & 0.0029\end{array}$

Note: Moldboard plough, $\mathrm{Qh}_{1}$ is the weight determined by $\mathrm{AHP} ; \mathrm{Qh}_{2}$ is the weight determined by entropy weight method; $\mathrm{Qh}_{3}$ is the weight combination. Rotary cultivator, $\mathrm{Qx}_{1}$ is the weight determined by $\mathrm{AHP} ; \mathrm{Qx}_{2}$ is the weight determined by entropy weight method; $\mathrm{Qx}_{3}$ is the weight combination.

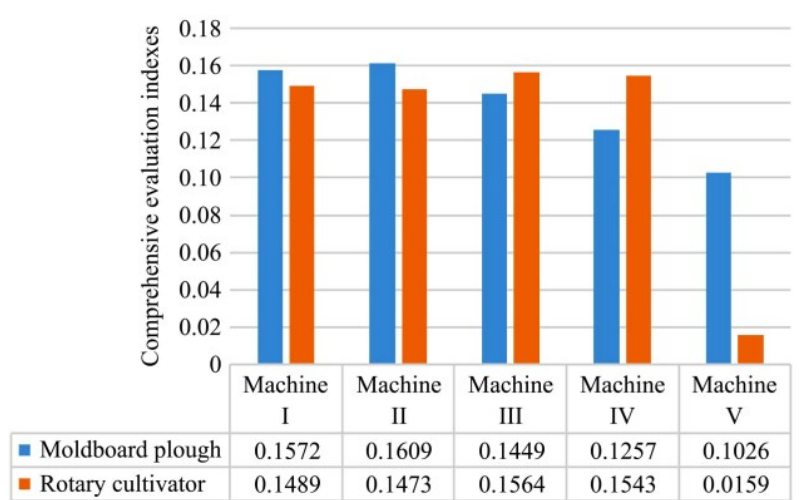

Figure 4 Evaluation results of machine tillage equipment

\section{Conclusions}

1) Based on the existing national and industry standards for agricultural machinery, the selection evaluation system was constructed for wheat and maize double cropping field operation machinery, and the selection evaluation model was established with an improved fuzzy comprehensive evaluation method. The method of combining subjective weight with objective weight was used to obtain the weight value of each index in the evaluation system, which overcomes the shortcoming of the previous single weighting method that cannot consider the subjective and objective information of each index at the same time, and makes the judgment more realistic.

2) The evaluation index values were obtained through field measurements of the plows and rotary cultivators used in the field preparation link, and the selection evaluation model constructed by this research was verified. The test showed that the results obtained through the evaluation model were consistent with the actual local conditions. Similarly, this method has good practical significance and provides an effective method for agricultural machinery selection for agricultural machinery users.

\section{Acknowledgements}

The authors acknowledge that this work was supported by the National Key Research and Development Program of China project (Grant No. 2017YFD0301106), the National Natural Science Foundation of China (Grant No. 52075149), Scientific and Technological Project of Henan Province (Grant No. 212102110029), High-tech Key Laboratory of Agricultural Equipment and Intelligence of Jiangsu Province (Grant No. JNZ201901), the Colleges and Universities of Henan Province Youth Backbone Teacher Training Program (Grant No. 2017GGJS062), the Postgraduate Education Reform Project of Henan Province (Grant No. 2019SJGLX063Y).

\section{[References]}

[1] Li G G. Research on the application of advanced agricultural technology in agricultural machinery. Agriculture of Henan, 2016; 23: 125-126. (in Chinese)

[2] Yang C, Mi L, Gao P F, Chai Z H. On the present situation and development trend of agricultural mechanization in China. China Southern Agricultural Machinery, 2019; 50(7): 19. (in Chinese)

[3] Du Y F, Fu S H, Mao E R, Zhu Z X, Li Z. Development situation and prospects of intelligent design for agricultural machinery. Transactions of the CSAM, 2019; 50(9): 1-17. (in Chinese)

[4] Liu M H. Research on the present situation and development mode of agricultural mechanization in China. Nong Min Zhi Fu Zhi You, 2018; 15: 164. (in Chinese)

[5] Shi X H. Current situation and countermeasures of agricultural mechanization in agricultural engineering. South China Agriculture, 2018; 
12(21): 146-147. (in Chinese)

[6] Ning B Q, Peng W S, Guo S Q, Shan Z P. Research on comprehensive evaluation of agricultural machinery based on dynamic combination weighting. Journal of Agricultural Mechanization Research, 2015; 37(7): 79-82, 96. (in Chinese)

[7] Gao Q S, Cao G Q, Zhu M, Yang Y T. Research on selection system of total tiller on facility agriculture. Journal of Chinese Agricultural Mechanization, 2013; 34(6): 148-152, 158. (in Chinese)

[8] Pan R Q, Liu J, Song D Y. Agricultural land classification based on fuzzy comprehensive analysis. Transactions of the CSAE, 2014; 30(18): 257-265. (in Chinese)

[9] Liu G M, Yang J S, He L D, Yu S P, Yao R J, Lyu Z Z. Fuzzy comprehensive evaluation based assessment of soil alkaline desertification in typical arid area of Xinjiang. Transactions of the CSAE, 2011; 27(3): 1-5. (in Chinese)

[10] Yang J Y, Ou C, Li Q, Zhang X, Zhang C, Zhu D H. Fuzzy synthetic evaluation of soil nutrients in cultivated land based on cloud model in Da'an City, Jilin Province. Transactions of the CSAM, 2018; 49(1): 251-257. (in Chinese)

[11] Yue T L, Peng B Z, Yuan Y H, Gao Z P, Zhang H, Zhao Z H. Modeling of aroma quality evaluation of cider based on principal component analysis. Transactions of the CSAE, 2007; 23(6): 223-227. (in Chinese)

[12] Liu B, Jiao G. Evaluation method of suitability for agricultural machinery. Transactions of the CSAM, 2006; 37(9): 100-103+82. (in Chinese)

[13] Zhao H S, Chen C, Hu Z Q, Li L M. Evaluation of intensive urban land use and analysis of obstacle factors in northern slope of Tianshan mountains. Transactions of the CSAE, 2018; 34(20): 258-266. (in Chinese)

[14] Hu W Z, He K, Jin C Q, Geng D Y, Zhang G H, Lu X F. FMECA method based on fuzzy comprehensive evaluation. Transactions of the CSAM, 2018; 49(S1): 332-337. (in Chinese)

[15] Wang J C, Xi L, Zhao X L, Ma X M, Cao D L, Xu X. Data normalization of leaf color based on fuzzy comprehensive evaluation for visualization model. Transactions of the CSAE, 2011; 27(11): 155-159. (in Chinese)

[16] Wu P, Jia C H, Fan S Y, Sun Y G. Principal component analysis and fuzzy comprehensive evaluation of fruit quality in cultivars of cherry.
Transactions of the CSAE, 2018; 34(17): 291-300. (in Chinese)

[17] Yang Y, Pan Y J, Liang S C. Fuzzy comprehensive evaluation of auto-driven micro-cultivator quality. Transactions of the CSAE, 2008; 24(2): 140-144. (in Chinese)

[18] Gong Y, Zhang X, Liu Y, Wang G, Chen X, Chen X B. Comprehensive evaluation method for applicability of plant protection machinery based on analytic hierarchy process. Transactions of the CSAM, 2016; 47(9): 73-78.

[19] Zhang W P, Zheng Z A, Wang G, Gao Z J, Yang B L, Wang J C. Establishment of evaluation model for tobacco field machinery selection. Transactions of the CSAE, 2015; 31(S1): 102-109. (in Chinese)

[20] Fu Q, Yang G L, Jin J L. Selection of agricultural machinery types and based on PPC model. Transactions of the CSAM, 2003; 34(1): 101-103. (in Chinese)

[21] Kang H Y, Li Z, Wei Z K, Li C X. Mode choice and optimization of harvester based on second-class indefinite comprehensive judgment. Journal of Agricultural Mechanization Research, 2005; 27(1): 100-102. (in Chinese)

[22] Wang Q Y, Wang F L. Application of grey correlation degree analysis method in the evaluation of agricultural equipment selection. Journal of Agricultural Mechanization Research, 2014; 36(8): 46-48, 58. (in Chinese)

[23] Xiang X, Luo Y, Cheng H S, Shen Yu J, Wang Y C, Zhang Y H. Biogas engineering technology screening based on analytic hierarchy process and fuzzy comprehensive evaluation. Transactions of the CSAE, 2014; 30(18): 205-212. (in Chinese)

[24] Fang Y X, Yang P L, Song S L, Du J, Xue Y D, Su Y P. Secondary fuzzy comprehensive evaluation model for ecosystem health of irrigation district and its application. Transactions of the CSAE, 2011; 27(11): 199-205. (in Chinese)

[25] Huang G Q, Han L J, Liu X, Yang Z L. Establish of evaluation system for integrated agricultural mechanization engineering technology. Transactions of the CSAE, 2012; 28(16): 74-79. (in Chinese)

[26] GBT 14225-2008. Mouldboard plough. 2008; 17p. (in Chinese)

[27] NYT 742-2003. Operation quality of mouldboard plough. 2003; 3p. (in Chinese)

[28] DGT 087-2019. Mouldboard plough. 2019; 4p. (in Chinese)

[29] GBT 5668-2017. Rotary tiller. 2017; 7p. (in Chinese) 